\title{
Dengue with hypokalemic periodic paralysis: A case report and review
}

\author{
Sumeet David $^{1 *}$, Aroma Oberoi ${ }^{2}$ \\ ${ }^{I}$ Assistant professor, department of medicine, CMC \& H, Ludhiana \\ ${ }^{2}$ Professor and $H O D$, department of microbiology, $C M C \& H$, Ludhiana \\ *Corresponding author E-mail: sumeetdavid_2007@yahoo.co.in
}

Copyright $\odot 2014$ Dr. Sumeet David, Dr. Aroma Oberoi. This is an open access article distributed under the Creative Commons Attribution License, which permits unrestricted use, distribution, and reproduction in any medium, provided the original work is properly cited.

\begin{abstract}
A 38 year old man was admitted to an emergency department with complains of fever for 2 days and bilateral upper and lower weakness. Dengue NSI came to be positive. Platelets were also found to be on the lower side. Serum potassium found to be on the lower side .power on the lower limb 3/5 and upper limb 4/5.power improved after potassium replacement.
\end{abstract}

Keywords: Use about five key words or phrases in alphabetical order, separated by commas.

\section{Case report}

A 38 year old man was admitted to the emergency department with complaints of fever for two days and bilateral upper and lower limb weakness. Serum potassium was found to be on the lower side .Dengue NSI positive .platelets were also found on the lower side.

Power improved after potassium replacement. Platelets also started to improve gradually .rest of the reports found to be normal.

\section{Discussion}

Dengue was regarded as a no neurotropic virus. There are however recent reports on neurotropism or neuroinvasion of dengue virus infection. [2], [3] the syndrome of acute pure motor weakness in dengue was quite characteristic and has not been comprehensively evaluated in earlier reports. The clinical picture simulated Guillain-Barre (GB) syndrome. The presence of fever at the time of weakness, normal nerve conduction studies and the absence of albumin cytological dissociation and response with potassium supplement excluded the possibility of GB syndrome.[2] Familial periodic paralysis was unlikely because there was no family history of episodic motor weakness and this being their first episode. The pathology of neurological manifestation is multiple and includes neurotropic effect of dengue virus, systemic effect of dengue infection, and immune-mediated injury. [4] Jha and Ansari [5] reported three confirmed cases of dengue infection causing acute reversible-hypokalemic pure motor quadriparesis. Gupta et al. [1] reported two confirmed cases of hypokalemic periodic paralysis precipitated by upper respiratory tract infection of viral etiology. They also observed that potassium supplementation resulted in rapid improvement of symptoms. Santos et al. [6] reported GB syndrome in the course of dengue. The clinical profile of dengue is changing, and the neurological manifestations are reported more frequently. Widodo et al.[2] observed prevalence of hypokalemia in $23 \%(\mathrm{n}=105)$ of the hospitalised patients with infectious disease and Kalita et al. studied 16 patients with dengue fever with quadriparesis, in seven, the pure motor quadriparesis was due to myositis.[6] Hypokalemia in association with infectious diseases, particularly in dengue fever, has been reported. Hypokalemic paralysis secondary to chikungunya fever has also been documented. [7] The putative mechanism of the hypokalemia in our patients could be either due to redistribution of potassium in cells or transient renal tubular abnormalities leading to increased urinary potassium wasting. Preliminary investigations were not suggestive of renal tubular abnormalities. However, transient self-limiting 
renal tubular defects secondary to infections cannot be ruled out. Increased catecholamine levels in response to stress of the infection and secondary insulin release may result in an intracellular shift of potassium and hypokalemia. Anabolic states following rapid cell re-growth in patients of pernicious anemia treated with vitamin B12 and in patients with neutropenia after treatment with a granulocyte-macrophage colony stimulating factor can result in hypokalemia due to a potassium shift into cells.

\section{References}

[1] Gupta M, Lehl SS, Singh R, Sachdev A. Hypokalemic periodic paralysis;2 novel causes. Internet J Neurol. 2009; 12:1

[2] Widodo D, Setiawan B, Chen K, Nainggolan L, Santoso WD. The prevalence of hypokalemia in hospitalized patients with infectious diseases problem at Cipto Mangunkusumo Hospital, Jakarta. Acta Med Indones. 2006; 38:202-5.

[3] Kalita J, Misra UK, Mahadevan A, Shankar SK. Acute pure motor quadriplegia: Is it dengue myositis? Electromyogr Clin Neurophysiol. 2005; 45:357-61.

[4] Pancharoen C, Thisyakorn U. Neurological manifestations in dengue patients. Southeast Asian J Trop Med Public Health. 2001; 32:341-5.

[5] Jha S, Ansari MK. Dengue infection causing acute hypokalemic quadriparesis. Neurol India. 2010; 58:592-4.

[6] Santos NQ, Azoubel AC, Lopes AA, Costa G, Bacellar A. Guillain-Barré syndrome in the course of dengue: Case report. Arq Neuropsiquiatr. 2004; 62:144-6.

[7] Rampal, Sharda M, Meena H. Hypokalemic paralysis following Chikungunya fever. J Assoc Physicians India. 2007; 55:598.

[8] Singer GG, Brenner BM, et al. Harrison's principles of internal medicine. 17th Ed. New York: Mcgraw-Hill Companies; 2008. Fluid and electrolyte disturbances; pp. 274-85. 